\title{
Progress towards Schistosomiasis Elimination: Application of Sensitive Diagnostic Techniques
}

Amal Farahat Allam ${ }^{1 *}$, Hoda Fahmy Farag', Mervat Mostafa Osman², Nancy Abd-elkader Hagras ${ }^{2}$, Mohamed Abdel Rahman Ahmed ${ }^{3}$, Adel Zaki $^{4}$, Rashad Abdul-Ghani ${ }^{5}$ and Amel Youssef Shehab

${ }^{1}$ Department of Parasitology, Medical Research Institute, Alexandria University, Alexandria, Egypt

${ }^{2}$ Department of Medical Laboratory, Faculty of Applied Medical Sciences, Pharos University in Alexandria, Alexandria, Egypt

${ }^{3}$ Department of Clinical Pathology, Military Medical Academy, Armed Forces Hospital, Alexandria, Egypt.

${ }^{4}$ Department of Medical Statistics, Medical Research Institute, AlexandriaUniversity, Alexandria, Egypt

${ }^{5}$ Department of Parasitology, Faculty of Medicine and Health Sciences, Sana'a University, Yemen

\begin{abstract}
Objective: Pursuing successful control programs aiming at schistosomiasis elimination, the diagnostic performance of Kato-Katz, urine Circulating Cathodic Antigen (CCA) point of care rapid test and real-time PCR techniques were compared for the detection of Schistosoma mansoni among school children with different infection intensities.
\end{abstract}

Methods: Stool and urine samples were collected from 110 school children after obtaining the consent of their parents and school guardians. The study was conducted in Motobus village, Kafr El-Sheikh governorate, Egypt. The collected stool samples were examined after Kato Katz (two slides, $41.7 \mathrm{mg}$ each). Urine specimens were examined for S. haematobium by filtration technique and were tested for S. mansoni by POC-CCA. For of real time PCR, part of each stool sample was kept at $-20^{\circ} \mathrm{C}$ until used.

Results: All the examined children were negative for S. haematobium. The performance of the three tests revealed that examination of double Kato-Katz smears detected S. mansoni infection in $51 \%$ of school children, where most of them had low infection intensity (64\%). However, higher S. mansoni prevalence of $83 \%$ and $60 \%$ were diagnosed by real-time PCR and CCA, respectively. It was also found that real-time PCR detected a higher proportion of S. mansoni negative cases after Kato-Katz- compared to CCA $(70 \%$ and $22 \%)$ respectively. Kato-Katz, CCA and real time PCR showed similar results with moderate and heavy infection intensities. Increasing the number of cycles of real time PCR to 40 cycles could detect the low infection intensity.

Conclusion: To move towards schistosomaisis elimination, real time PCR due to its great sensitivity is suitable for established control programs to detect cases overlooked by Kato-Katz technique and CCA test. The adoption of this technique can enhance the monitoring of Schistosomiasis mansoni control measures in pre-elimination or elimination settings.

Keywords: Schistosoma mansoni; Kato-Katz; Circulating cathodic antigen point of care cassette test (CCA-POC); SYBR green; Real-time PCR

\section{Introduction}

Schistosomiasis is a chronic disease caused by infection with parasitic worms of the genus Schistosoma. It is considered one of the neglected diseases responsible for disabilities each year around the globe $[1,2]$. Approximately 240 million human individuals are infected globally and about 700 million people are living at risk of this infection [3].

Schistosomiasis control has received support through global alliances and partnerships. A cardinal step was taken by the WHO in setting out a clear strategy for the scale up of preventive chemotherapy and assistance to countries to appraise their future praziquantel needs until 2020 and beyond. Its current strategy for the control of schistosomiasis is the reduction of morbidity through regular treatment with praziquantel of populations at risk [4,5]. Efforts to control morbidity of the disease are being stepped up worldwide. In some countries, there are existent prospects to turnover from schistosomiasis control into transmission control and eventually elimination [6]. What is more, elimination in selected areas by 2025 is now an aim $[7,8]$.

In conditions where elimination of schistosomiasis is aimed at, case detection may pose a problem as the commonly used methods lack the necessary sensitivity to accurately determine the prevalence of schistosomiasis or low infection intensity $[9,10]$. Active surveillance should rely upon proper diagnosis, particularly in situations of low intensity [9-11].
Kato-Katz is the method recommended for diagnosis of $S$. mansoni infection by the WHO for its high specificity, handiness and cost effectiveness [12]. The concern that Kato-Katz method misses $S$. mansoni infection in a proportion of cases in regions of low prevalence and intensity has a very important implication, principally when it is used in monitoring the effectiveness of preventive chemotherapy [13].

Serodiagnostic assays designed for the detection of specific antischistosome antibodies and antigens have been developed over the years $[14,15]$. However, the drawback intrinsic to antibodies assays is the discrimination between active and old infections [15]. In addition, blood collection is not easily applicable for field studies in endemic areas $[14,15]$.

The commercially available point of care urine Circulating Cathodic Antigen (CCA-POC) has been shown to be a promising approach to

*Corresponding author: Amal Farahat Allam, Department of Parasitology, Medical Research Institute, Alexandria University, Alexandria, Egypt, Tel: 02034286496; E-mail: amalalam2005@yahoo.com

Received: August 10, 2018; Accepted: September 20, 2018; Published: September 27, 2018

Citation: Allam AF, Farag HF, Osman MM, Hagras NA, Ahmed MAR, et al. (2018) Progress towards Schistosomiasis Elimination: Application of Sensitive Diagnostic Techniques. Prim Health Care 8: 305. doi: 10.4172/2167-1079.1000305

Copyright: (C) 2018 Allam AF, et al. This is an open-access article distributed under the terms of the Creative Commons Attribution License, which permits unrestricted use, distribution, and reproduction in any medium, provided the original author and source are credited. 
the identification of active $S$. mansoni infection and to the assessment of treatment efficacy [16,17]. POC diagnosis is beneficial not only for individual patients but it allows as well for rapid mapping of disease prevalence and the acceleration of schistosomiasis control programs, factors which are imperative to meet the 2020 goals [18].

PCR method displayed high sensitivity and specificity for the detection of $S$. mansoni DNA in stool samples, yet it gave negative results among few cases positive by microscopy [19]. Lodh et al. [20] showed that the diagnosis of $S$. mansoni from urine samples by PCR is an effective way to diagnose light infections and thus enhance the effectiveness of surveillance and control programs of schistosomiasis.

Real time PCR assay using SYBR Green (fluorescent based technology) and Taq Man probe for the detection and quantification of S. mansoni DNA in fecal samples were developed and evaluated as a diagnostic method to study the epidemiology of schistosomiasis [21].

The present study aimed at comparing the performance of urine Circulating Cathodic Antigen (CCA) cassette test and real time PCR as well as PCR Ct values in cases of $S$. mansoni with different intensities as diagnosed by Kato-Katz. Focus for adequate management for schistosomiasis transmission interruption and elimination was considered.

\section{Methods}

\section{Study Area}

The study was carried out in Motobus village, El-Riyad District, Kafr El-Sheikh governorate, Egypt. Motobus is $100 \mathrm{~km}$ away from Alexandria. Farming is the major source of economic activity and agriculture employs most of the work force.

\section{Administrative design and ethical considerations}

For the conduction of the present work, ethical clearance was permitted by the ethical committee of the Medical Research Institute and parasitology department. Approval of the study was obtained from the Egyptian Ministry of Health and Population and the Administration of Health Affairs in Kafr El-Sheikh governorate. Preliminary meetings were held with the directors and teachers of the school to explain the outline of the study. Informed consents were obtained from school guardians and parents before participation of their children in the study. Ethically, all cases with S. mansoni and other parasites (diagnosed after Kato-Katz) were treated with conventional drugs.

Study subjects and sample size: Based on a 35\% infection rate of $S$. mansoni diagnosed previously in this area $[22,23]$ and on the hypothesis that the sensitivity of the tests used in the present study is around $90 \%$ and accepting a margin of error \pm 7 at level of confidence $95 \%$, a sample size of 110 pupils randomly selected were enrolled in the study. Children aged 6-12 years in Arab El-Mahder primary school were asked to provide stool and urine samples.

Collection of urine and stool samples: The school was visited on two consecutive days every week for collection of stool and urine samples. On the first day, tightly closed plastic containers labelled with student's identification number, name and class, were distributed. On the next day, the containers were collected from all students enrolled in the study and returned to the parasitology laboratory in the Medical Research Institute. All the collected stool samples were examined microscopically after Kato-Katz technique $(41.7 \mathrm{mg} / \mathrm{slide}, 2$ slides for each sample) [24]. A portion of each fecal specimen was stored at $-20^{\circ} \mathrm{C}$ for further processing by real time PCR. A single midstream urine sample was collected from each child and was examined by filtration technique for the presence of S. haematobium. Part of each urine sample was stored at $-20^{\circ} \mathrm{C}$ until the CCA assay was performed.

\section{Laboratory techniques:}

CCA cassette test: CCA assay was obtained from Rapid Medical Diagnostics (Pretoria, South Africa). In brief, one drop of each urine sample was added to the circular well; the CCA if present in the urine sample binds to the labelled monoclonal antibody immobilized on the membrane of the well. The buffer solution then runs over the strip where the antigen-antibody complex attaches to another monoclonal antibody immobilized at the test line developing a pink color. The other line is a control, which should always give a pink color to make sure the test works correctly $[16,17]$.

DNA extraction and real time PCR: Extraction of egg DNA from all stool specimens was done by using QIAGEN amp DNA stool mini kit (Qiagen, Hilden, Germany) according to the manufacturer's instructions. For detection of $S$. mansoni specific DNA, primers targeting the $28 \mathrm{~S}$ rDNA region from S. mansoni ( $\mathrm{SmF} / \mathrm{SmR})$ were used by Sandoval et al. [25] to diagnose $S$. mansoni from urine samples. These primers were used in the present study to amplify the extracted S. mansoni DNA from stool samples. Primers SmF GAGATCAAGTGTGACAGTTTTGC and SmRCAGTGCGCGCGTCGTAAGC, rDNA (ribosomal DNA) region localization $28 \mathrm{~S}$ were selected to amplify a fragment of $350 \mathrm{bp}$, which was detected by the SYBR Green [21]. Positive control sample for $S$. mansoni DNA was used. In addition, DNA controls of other parasites were extracted from routine stool samples submitted to department of parasitology, Medical Research Institute, Alexandria University. A DNA negative control was obtained from the stool specimen of parasite free individual.

PCR included $10 \mu \mathrm{L}$ of extracted DNA from each stool sample, $0.1 \mu \mathrm{L}$ of each S. mansoni primer (forward and reverse), $12.5 \mu \mathrm{L}$ SYBR Green universal PCR master mix as well as water free RNAase added in the reaction tube to a final volume of $25 \mu \mathrm{L}$. The real time PCR was then performed under the thermal profile as follows: An initial denaturation step at $95^{\circ} \mathrm{C}$ for 15 min was firstly carried out. 40 cycles of amplification were performed $\left(94^{\circ} \mathrm{C}\right.$ for $20 \mathrm{~s}, 61^{\circ} \mathrm{C}$ for $20 \mathrm{~s}$ and $72^{\circ} \mathrm{C}$ for $30 \mathrm{~s}$ ). Well defined DNA extracted from S. mansoni positive stool samples was used as positive control and included in each PCR run. Melting curve analysis was done to determine the purity and specificity of the amplified product. It was subsequently performed after PCR run, by increasing temperature slowly from $72^{\circ} \mathrm{C}$ to $95^{\circ} \mathrm{C}$ for one min, then at $55^{\circ} \mathrm{C}$ for $30 \mathrm{~s}$ and finally at $95^{\circ} \mathrm{C}$ for $30 \mathrm{~s}$ [21].

Intensity of infection: Intensity was determined by microscopy after Kato-Katz and compared with the cycle threshold $(\mathrm{Ct})$ value of the real-time PCR.

\section{Statistical analysis}

Data were analyzed using IBM SPSS for Windows, Version 20.0 (Armonk, NY: IBM Corp). The statistical program was utilized for both data presentation and statistical analysis of the results. For descriptive analysis, the prevalence by different methods was articulated in percentages, while the median was used to present the real-time PCR Ct values. Geometric mean was used to express the S. mansoni egg counts (GMEC) [26]. Confidence Interval (CI) of $95 \%$ was applied as measures of central tendency and dispersion respectively for normally distributed quantitative data. The final judgment of the results for each sample was based on the three tests (KK, PCR and CCA), the positive and negative assessment was based 
on the next predictions according to Lodh et al. [20]. If Kato-Katz, CCA and real time PCR are positives the results are True Positives (TP). If the three methods gave negative results, then True Negative (TN). If KK positive and CCA or PCR negative then the sample considered False Negative (FN). The samples are False Positive (FP) when PCR or KK are negative and CCA positive. Built on these assumptions, the results of all specimens collected were classified and all diagnostic parameters were calculated at 95\% CI using Med Calc 12.4.0 (Med Calc Software, Belgium). The diagnostic parameters of the three methods were evaluated by establishing a reference standard incorporating all the positive cases by KK, CCA and real time PCR. Kappa agreement $(\mathrm{K})$ test was applied for measuring the agreement between the results of the diagnostic tests (at $\mathrm{k}<0.2$ poor agreement, $\mathrm{k}$ 0.2-0.4 fair agreement, $\mathrm{k}>0.4-0.6$ moderate agreement, $\mathrm{k}>0.6$ high

\begin{tabular}{|l|c|c|c|c|c|}
\hline Test & True positive & False positive & True negative & False negative & Total \\
\hline KK & 56 & 0 & 16 & 38 & 110 \\
\hline CCA & 63 & 3 & 13 & 31 & 110 \\
\hline PCR & 91 & 0 & 16 & 3 & 110 \\
\hline
\end{tabular}

Table 1: Evaluation of the performance of Kato Katz (K-K), circulating cathodic antigen (CCA-POC) and real time PCR for detection of S. mansoni among the examined school children. agreement). Spearman's non-parametric coefficient ( $\mathrm{r}$ ) was used to detect the correlation between the $\mathrm{Ct}$ values and intensity of infection. In all statistical tests, significance was accepted as $\mathrm{p}<0.05$ [27].

\section{Results}

By using the urine filtration technique, all samples were negative for S. haematobium.

The performance of the three diagnostic methods to detect $S$. mansoni infection among the examined school children is presented in Table 1 and Figure 1. Out of 110 tested samples, 94 cases were true positive (by KK+ CCA+PCR). Real time PCR gave the highest positive (91 true positives) results compared to the three tests. The number of false negatives was highest with KK (38 cases).

Table 2 showed the calculated diagnostic parameters including sensitivity and specificity of KK $(60 \%, 100 \%)$, CCA $(67 \%, 81 \%)$ and PCR (97\%, 100\%). The Positive Predictive Values (PPVs) were relatively similar, ranging from $96 \%$ to $100 \%$ for the three used methods. The Negative Predictive Values (NPVs) were inconsistent. Moreover, the positive and negative likelihood ratios were reflective of PPVs and NPVs for the used diagnostic methods.

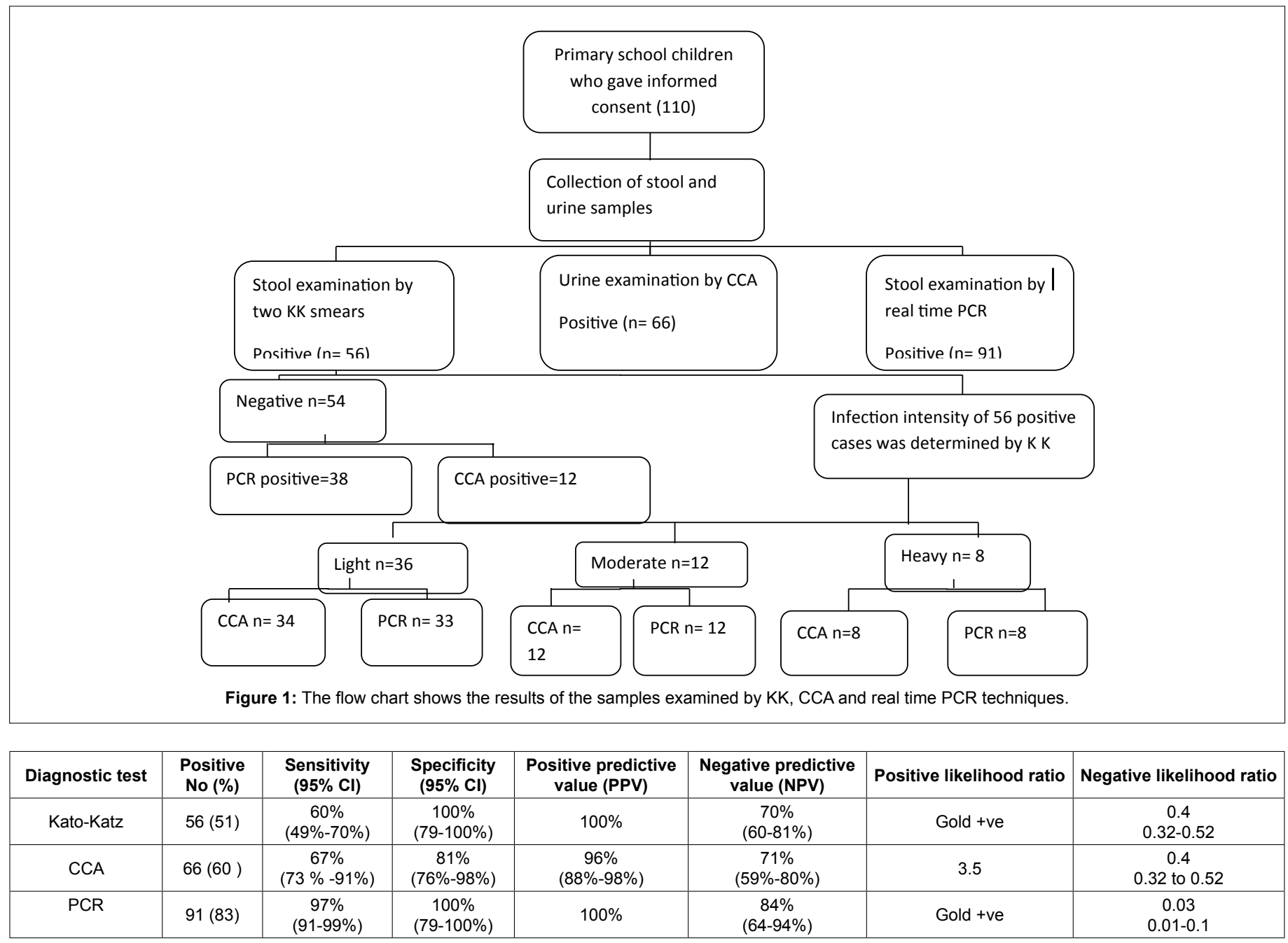

$\mathrm{Cl}=$ confidence interval.

Table 2: Prevalence, sensitivity, specificity, predictive values, and likelihood ratios of the three diagnostic tests for detection of $S$. mansoni infection among 110 examined children. 


\section{The agreement between the different diagnostic techniques in the detection of $S$. mansoni}

Statistical analysis showed a kappa index of 0.75 indicating high agreement between Kato-Katz and CCA. Fourteen cases showed discordant results. By comparing the results of the real time PCR and Kato-Katz, 53 patients gave concordant positive results and 41 showed discordant results. Statistically, a fair agreement was detected between both techniques $(\mathrm{K}=0.25)$. Also, CCA and real time PCR showed fair agreement with discordant results among 33 cases and the kappa index was 0.31 (Table 3).

\section{Comparison of CCA, real time PCR performance and Ct values with Kato-Katz according to $S$. mansoni infection intensity}

Table 4 and Figure 2 illustrate the distribution of the positive cases by the Kato-Katz according to the intensity of infection. $64.3 \%$ of positive cases had light infection intensity, $21.4 \%$ and $14.2 \%$ showed moderate and heavy intensity. Results of the CCA and PCR are presented in the different egg count categories. All cases with moderate and heavy infections were positive by both techniques. Among the light intensity category, both CCA and real time PCR missed cases with equal or less than 12 eggs. The table shows as well the range and the median PCR $\mathrm{Ct}$ values in the different categories. Statistically, there was a negative correlation between the $\mathrm{Ct}$ values (Figure 3 ) and $S$. mansoni egg counts

\begin{tabular}{|c|c|c|c|}
\hline \multirow[b]{2}{*}{ CCA } & \multicolumn{2}{|c|}{ Kato-Katz } & \multirow{2}{*}{ Tota } \\
\hline & Positive & Negative & \\
\hline Positive & 54 & 12 & 66 \\
\hline Negative & 2 & 42 & 44 \\
\hline Total & 56 & 54 & 110 \\
\hline \multicolumn{4}{|l|}{$k=0.75$} \\
\hline \multirow[b]{2}{*}{ PCR } & \multicolumn{2}{|c|}{ Kato-Katz } & \\
\hline & Positive & Negative & Total \\
\hline Positive & 53 & 38 & 91 \\
\hline Negative & 3 & 16 & 19 \\
\hline Total & 56 & 54 & 110 \\
\hline \multicolumn{4}{|l|}{$k=0.25$} \\
\hline \multirow[b]{2}{*}{ PCR } & \multicolumn{2}{|c|}{ CCA } & \\
\hline & Positive & Negative & Total \\
\hline Positive & 62 & 29 & 91 \\
\hline Negative & 4 & 15 & 19 \\
\hline Total & 66 & 44 & 110 \\
\hline$k=0.31$ & & & \\
\hline
\end{tabular}

Table 3: Agreement between Kato-Katz, CCA and real time PCR for the detection of S. mansoni infection.

\begin{tabular}{|l|c|c|c|}
\hline $\begin{array}{l}\text { Egg count } \\
\text { category } \\
\text { (Kato- Katz) }\end{array}$ & $\begin{array}{c}\text { CCA positive } \\
\text { No (\%) }\end{array}$ & $\begin{array}{c}\text { PCR positive } \\
\text { No (\%) }\end{array}$ & $\begin{array}{c}\text { Ct value of positive PCR } \\
\text { per egg count category } \\
\text { Range (Median) }\end{array}$ \\
\hline Negative ( $\mathrm{n}=54)$ & $12(22.2)$ & $38(70.37)$ & $\begin{array}{c}8.83-37.92 \\
31.92\end{array}$ \\
\hline $\begin{array}{l}\text { Light<100 } \\
(\mathrm{n}=36,64.3 \%)\end{array}$ & $34(94.4)$ & $33(91.66)$ & $\begin{array}{c}18.78-38.13 \\
26.44\end{array}$ \\
\hline $\begin{array}{l}\text { Moderate (100- } \\
480) \\
(n=12,21.4 \%)\end{array}$ & $12(100)$ & $12(100)$ & $\begin{array}{c}17.29-34.25 \\
21.17\end{array}$ \\
\hline $\begin{array}{l}\text { Heavy>480 } \\
(\mathrm{n}=8,14.2 \%)\end{array}$ & $8(100)$ & $8(100)$ & $\begin{array}{c}16.22-24.85 \\
19.84\end{array}$ \\
\hline
\end{tabular}

*GMEC=73 eggs/gm

Table 4: Comparison between results of CCA, real time PCR and Ct values with Kato-Katz categorized by the number of $S$. mansoni eggs.

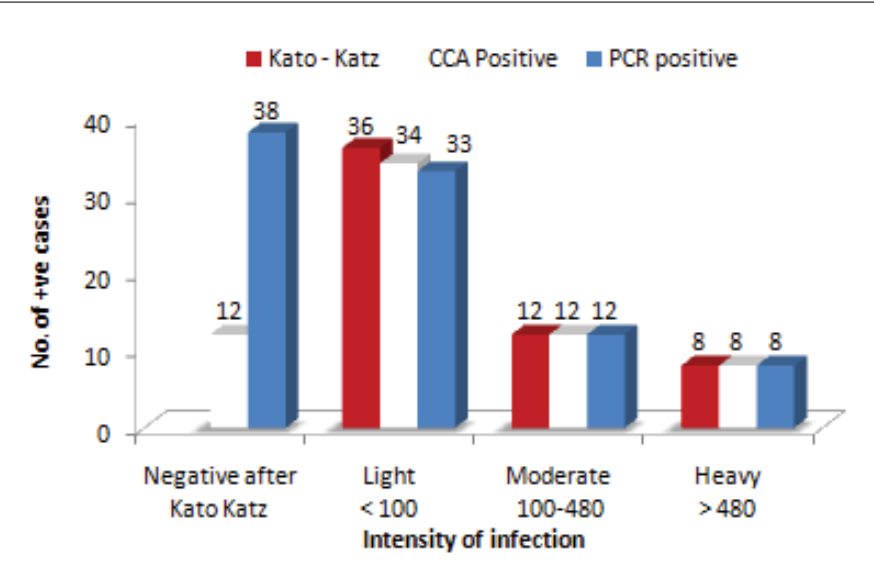

Figure 2: The performance of Kato Katz, CCA and real time PCR according to S. mansoni infection intensity.

but this correlation was not significant $(\mathrm{r}=0.208 ; \mathrm{n}=56 ; \mathrm{p}=0.124)$. The melting curve analysis determined the specificity of the sample product (Figure 4).

\section{Discussion}

Egypt has been overwhelmed by schistosomiasis for many years. Fortunately, due to the immense and sustained adoption of different control programs, the prevalence fell down to less than 2\% [13]. Despite of this control effort, noted foci of endemicity still exist, possibly due to a lack of improvement in rural sanitary conditions [6].

In the present study it was found that, despite the high prevalence in Motobus village ( $51 \%$ as diagnosed by Kato-Katz), the majority of children (64\%) had light infection while few had moderate and heavy infections. An explanation of the low GMEC may be a lower transmission potential due to low snail infection together with the availability of passive chemotherapy as rural health units and local physicians are present throughout the governorate. In addition, selfreferral for examination and treatment is common.

As we have moved towards low intensity and elimination of schistosomiasis, reconsideration of the present results in the light of intensity is needed. The wide transmission potential is existent even when small numbers of miracidia are released in water. In this study, the performance of Kato-Katz, CCA test and real time PCR were compared for the diagnosis of $S$. mansoni with different infection intensities. This study revealed that the highest prevalence $(83 \%)$ was detected by real time PCR, followed by CCA $(60 \%)$ while the lowest prevalence was diagnosed by Kato-Katz (51\%). Tchuente et al. and Coulibaly et al. $[16,18]$ reported that single urine CCA cassette test produced similar prevalence as multiple Kato-Katz thick smears. Regarding sensitivity, PCR showed a sensitivity of $97 \%$, while CCA currently in use as a point of care rapid diagnostic test has low sensitivity problems as KK (67\%, 60\% respectively). Similar results were reported by Lodh et al. [20].

By studying the agreement between the three techniques, statistical analysis showed high agreement between urine CCA cassette test and Kato-Katz and a fair agreement between Kato-Katz and real time PCR as well as between CCA and real time PCR. These results confirm the low sensitivity of Kato-Katz as compared to both techniques and the highest efficacy of real time PCR in the detection of S. mansoni. The fair agreement between Kato-Katz and PCR as well as between CCA and 
Citation: Allam AF, Farag HF, Osman MM, Hagras NA, Ahmed MAR, et al. (2018) Progress towards Schistosomiasis Elimination: Application of Sensitive Diagnostic Techniques. Prim Health Care 8: 305. doi: 10.4172/2167-1079.1000305

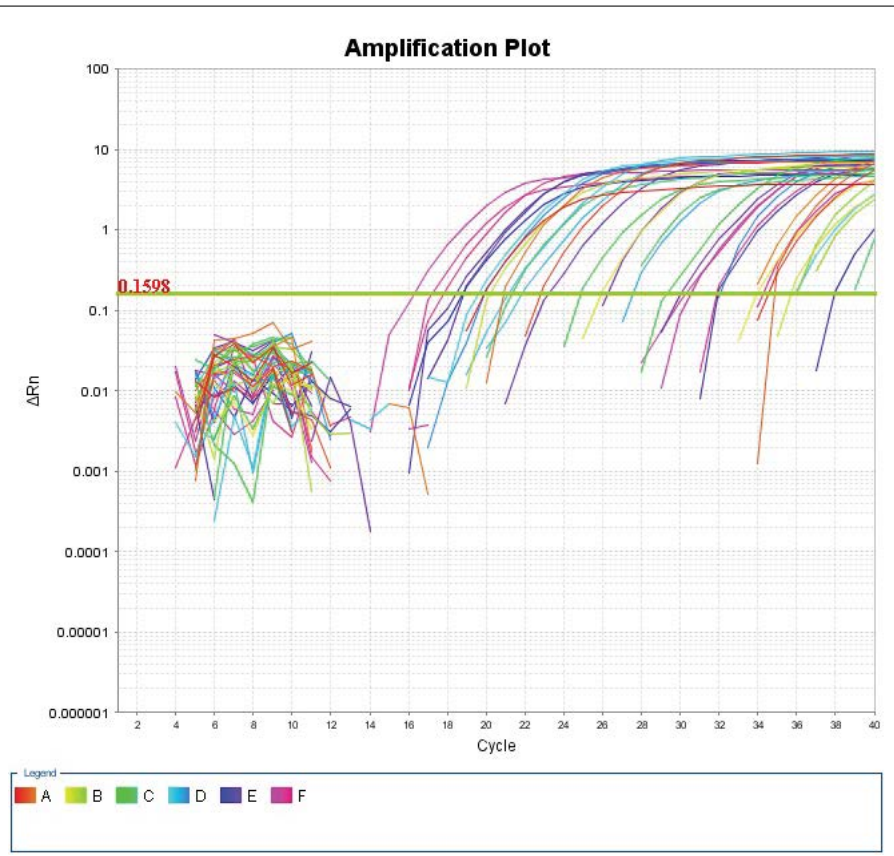

Figure 3: Amplification plot of the positive control as well as representative samples of positive real time PCR cases with Ct values ranging from 16.22 to 38.13 .

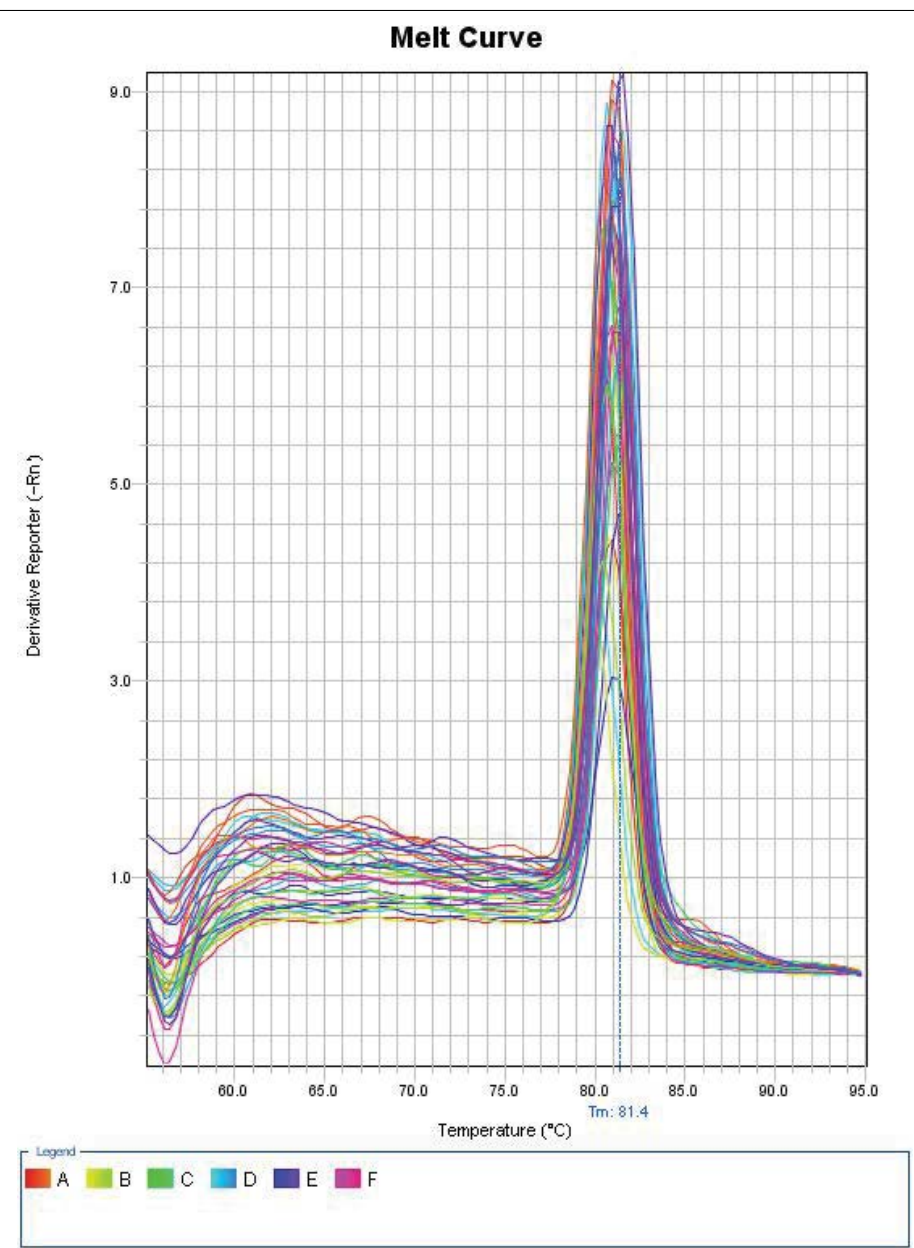

Figure 4: Real time PCR melting curve with a melting temperature specific to the amplified fragment $\left(\mathrm{Tm}=81.4^{\circ} \mathrm{C}\right)$. The melting curve of the positive control as well as the positive real time PCR cases. 
PCR means that the combination of Kato-Katz and or CCA tests with PCR will improve the diagnostic results more than combining KatoKatz with CCA test.

Concerning the discordant results, two cases were diagnosed only by Kato-Katz, three cases were diagnosed only by CCA while one case was detected by both Kato- Katz and CCA but missed by real time PCR and this may be attributed to specific inhibitors in stool or to DNA degradation during transportation and/or manipulation of the stool samples [21]. The two cases positive by Kato-Katz and negative by CCA could be explained by low intensity and small amount of antigen released. The three cases detected only by CCA, may be false positives or due to the presence of immature worms during the migration period to mesenteric veins before starting egg laying (egg negative/worm positive). Further studies in the laboratory and follow up of these cases may be required to address these issues.

Depending on the intensity of infection as estimated by KatoKatz, the three tests detected almost similar prevalence in moderate and heavy infections. Parallel observations were reported by several authors, they documented that the current commercially available CCA urine cassette test was appropriate for diagnosis of S. mansoni in moderate and heavy transmission areas [16-18]. Inconsistency between microscopy, CCA and PCR was observed in samples with low egg counts or low parasite DNA concentration. Real time PCR diagnosed $S$. mansoni positive cases approximately three folds (70.4\%) higher than CCA test (22.2\%) among those missed by Kato-Katz. Referring to real time PCR, the present results were similar to those of Hove et al. [21] who reported that the sensitivity of real time PCR was $100 \%$ for subjects with $S$. mansoni intensity more than 100 eggs. They also stated that discrepancies between real time PCR and microscopy were observed in samples with low intensity of infection.

The present study illustrated that real time PCR showed the best performance as it detected the highest positive cases in comparison to CCA and Kato-Katz. The high positive and negative predictive values were also indicative of PCR robustness. The use of real time PCR had the advantage of quantitative analysis, as shown by the negative correlation between $\mathrm{Ct}$ values and number of target copies [28-30]. Increasing the number of real time PCR cycles to 40 cycles could detect the low intensity of infection. The specificity of the real time PCR based on SYBR Green product was verified by the performance of melting curve analysis. A characteristic melting temperature of the amplicon distinguishes it from amplification artefacts that melt at lower temperatures with broader peaks $[29,30]$. When comparing the real time PCR with microscopy-based assays, the PCR is less labor intensive when many samples are to be examined. The real time PCR method also has the advantage of being less influenced by observer variation/bias as compared to microscopy [31]. CCA is rapid, easy to use, less time consuming than Kato-Katz, field applicable and the easiness to collect urine than stool samples are significant characteristics for this test $[16,32]$.

\section{Limitations}

The higher prevalence obtained with KK together with CCA and real time PCR techniques argue for the continuation of Mass Drug Administration (MDA) in endemic areas. The costs to apply these tests and control interventions may constitute a major constraint. It may be proper to deviate from mass drug administration to a test realty and selective treatment development.

\section{Conclusion}

In conclusion, Kato-Katz, CCA and real time PCR showed similar results with moderate and heavy infection intensities. Real time PCR was the strongest detector of S.mansoni positive cases missed by KatoKatz and CCA. It has also the advantage of quantitative analysis. To detect the low intensity of infection, it is recommended to increase the number of its cycles to 40 cycles.

The main strength of this study is the inclusion of the real time PCR and CCA results to provide more information on individual's infection status. The study also provides accurate diagnosis of S.mansoni and baseline for prospective studies. To proceed towards a goal of elimination, it is advised to begin the survey with Kato-Katz and then apply POC-CCA on the negatives to diagnose more cases and to detect egg-negative/worm-positive schistosomiasis. PCR should enact on the negative cases after Kato Katz and CCA. Efforts to reduce CCA and real time PCR costs are necessary to facilitate their large scale use.

\section{Acknowledgements}

We gratefully acknowledge the Military Medical Academy, the Armed Forces Hospital and the Department of Clinical Pathology that facilitated the achievement of this work. We appreciate the technical assistance of the Parasitology Department staff of the Medical Research Institute. We are also grateful to the Ministry of Health, the school directors and teachers, parents/guardians and the school children for their cooperation.

\section{References}

1. Gulland A (2012) Governments and drug companies pledge to eliminate 10 neglected tropical diseases by 2020. BMJ 344: e773.

2. Molyneux DH (2012) The 'Neglected Tropical Diseases': Now a brand identity; responsibilities, context and promise. Parasit Vectors 5: 1-23.

3. Sady H, Al-Mekhlafi HM, Ngui R, Atroosh WM, Al-Delaimy AK, et al. (2015) Detection of Schistosoma mansoni and Schistosoma haematobium by RealTime PCR with high resolution melting analysis. Int J Mol Sci 16: 16085-16103.

4. Colley DG, Bustinduy AL, Secor WE, King CH (2014) Human schistosomiasis Lancet 383: 2253-2264.

5. WHO (2017) Schistosomiasis. Fact sheet No. 115.

6. Cnops L, Tannich E, Polman K, Clerinx J, Van Esbroeck M (2012) Schistosoma real-time PCR as diagnostic tool for international travellers and migrants. Trop Med Int Health 17: 1208-1216.

7. WHO (2012) Elimination of schistosomiasis. Sixty fifth World Health Assembly (WHA 65.21).

8. WHO (2013) Schistosomiasis: Progress report 2001-2011 and strategic plan 2012-2020.

9. WHO (2007) Report of inter country meeting on strategy to eliminate schistosomiasis from the Eastern Mediterranean Region.

10. Stothard JR, Stanton MC, Bustinduy AL, Sousa-Figueiredo JC, van Dam GJ, et al. (2014) Diagnostics for schistosomiasis in Africa and Arabia: A review of present options in control and future needs for elimination. Parasitology 141: 1947-1961.

11. Utzinger J, Becker SL, van Lieshout L, van Dam GJ, Knopp S (2015) New diagnostic tools in schistosomiasis. Clin Microbiol Infect 21: 529-542.

12. WHO (2002) The prevention and control of schistosomiasis and soil transmitted helminthiasis.

13. Allam AF, Kader O, Zaki A, Shehab AY, Farag HF (2004) Assessing the marginal error in diagnosis and cure of Schistosoma mansoni in areas of low endemicity using Percoll and PCR techniques. Trop Med Int Health 14: 316- 321.

14. Grenfell RF, Coelho PM, Taboada D, de Mattos AC, Davis R, et al. (2014) Newly established monoclonal antibody diagnostic assays for Schistosoma manson direct detection in areas of low endemicity. PLoS One 9: e87777.

15. Gryseels B, Polman K, Clerinx J, Kestens L (2006) Human schistosomiasis Lancet 368: 1106-1118.

16. TchuemTchuenté LA, KuetéFouodo CJ, KamwaNgassam RI, Sumo L DongmoNoumedem C, et al. (2012) Evaluation of circulating cathodic antigen (CCA) urine-tests for diagnosis of Schistosoma mansoni infection in Cameroon. PLoSNegl Trop Dis 6: e1758. 
Citation: Allam AF, Farag HF, Osman MM, Hagras NA, Ahmed MAR, et al. (2018) Progress towards Schistosomiasis Elimination: Application of Sensitive Diagnostic Techniques. Prim Health Care 8: 305. doi: 10.4172/2167-1079.1000305

17. Sousa-Figueiredo JC, Betson M, Kabatereine NB, Stothard JR (2013) The urine circulating cathodic antigen (CCA) dipstick: A valid substitute for microscopy for mapping and point-of-care diagnosis of intestinal schistosomiasis. PLoS Negl Trop Dis 7: e2008.

18. Coulibaly JT, N'Gbesso YK, Knopp S, N'Guessan NA, Silue KD, et al. (2013) Accuracy of urine circulating cathodic antigen test for the diagnosis of Schistosoma mansoni in preschool-aged children before and after treatment. PLoSNegl Trop Dis 7: e2109.

19. Oliveira LM, Santos HL, Goncalves MM, Barreto MG, Peralta JM (2010) Evaluation of polymerase chain reaction as an additional tool for the diagnosis of low-intensity Schistosoma mansoni infection. Diagn Microbiol Infect Dis 68: 416-421.

20. Lodh N, Mwansa JCL, Mutengo MM, ShiffC J (2013) Diagnosis of Schistosoma mansoni without the stool: Comparison of three diagnostic tests to detect Schistosoma mansoni infection from filtered urine in Zambia. Am J Trop Med Hyg 89: 46-50.

21. Ten Hove RJ, Verweij JJ, Vereecken K, Polman K, Dieye L, et al. (2008) Multiplex real-time PCR for the detection and quantification of Schistosoma mansoni and S. haematobium infection in stool samples collected in northern Senegal. Trans R Soc Trop Med Hyg 102: 179-185.

22. Barakat RM (2013) Epidemiology of Schistosomiasis in Egypt: Travel through time: Review. J Adv Res 4: 425-432.

23. Allam AF, Kader O, Zaki A, Farag HF, Abdel Ghani R, et al. (2015) Detection of low-intensity Schistosoma mansoni infection by Percoll sedimentation and real time PCR techniques in a low-endemicity Egyptian setting. Trop Med Int Health 20: 658-664.
24. Katz N, Chaves A, Pellegrino J (1972) A simple device for quantitative stoo thick-smear technique in Schistosomiasis mansoni. Rev Inst Med Trop Sao Paulo 14: 397-400

25. Sandoval N, Siles-Lucas M, Perez-Arellano JL, Carranza C, Puente S, et al (2006) A new PCR-based approach for the specific amplification of DNA from different Schistosoma species applicable to human urine samples. Parasitology 133: $581-587$.

26. Montresor A (2007) Arithmetic or geometric means of eggs per gram are not appropriate indicators to estimate the impact of control measures in helminth infections. Trans R Soc Trop Med Hyg 101: 773-776.

27. Altman GA (1992) Practical statistics for medical research. Chapman and Hall: London, pp: 404-408.

28. Klein D (2002) Quantification using real-time PCR technology: Applications and limitations. Trends Mol Med 8: 257-260.

29. Gomes AL, Melo FL, Werkhauser RP, Abath FG (2006) Development of a real time polymerase chain reaction for quantitation of Schistosoma mansoni DNA. Mem Inst Oswaldo Cruz 101 Suppl 1: 133-136.

30. Hung YW, Remais J (2008) Quantitative detection of Schistosoma japonicum cercariae in water by real-time PCR. PLoS Negl Trop Dis 2: e337.

31. Lier T, Johansen MV, Hjelmevoll SO, Vennervald, Simonsen GS (2008) Rea time PCR for detection of low intensity Schistosoma japonicum infections in a pig model. Acta Trop 105: 74-80.

32. Clements MN, Corstjens PLAM, Binder S, Campbell CH Jr, de Dood CJ, et al (2018) Latent class analysis to evaluate performance of point-of-care CCA for lowintensity Schistosoma mansoni infections in Burundi. Parasit Vectors 11: 1-111. 